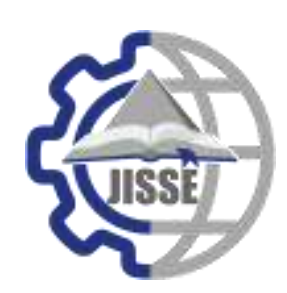

\begin{tabular}{c}
\hline \hline JISSE \\
ISSN: 2636-4425 \\
\hline \hline
\end{tabular}

\title{
Improving Productivity Using Six Sigma Methodologies: A Case Study on a Fluorescent Glass Tube Production Line
}

\author{
Mervat A. Badr ${ }^{1}$, Mahmoud Sayed ${ }^{2}$ \\ ${ }^{I}$ Mechanical Engineering Department, National Research Centre. \\ ${ }^{2}$ Mechanical Engineering Department, Canadian International College, Egypt.
}

\section{A R T I C L E I N F O}

\section{Article history:}

Received:12-02-2020

Accepted:10-05-2020

Online:13-05-2020

Keywords:

DMAIC,

Outer Diameter,

Sigma level,

Capability Index,

Part per Million,

Action Plan.

\begin{abstract}
A B S T R A C T
The objective of this study is to decrease the number of defects occurring through the manufacturing process of the fluorescent a glass tube using six sigma techniques performing cost analysis for the case under study; before and after improvement i.e. reduction of the number of defects. The case under study is applied on a glass tube production line in one of Toshiba El-Araby Industrial factories. It was observed that there are several of defects that were monitored through the study period of 9 months. These defects include variation in the outer diameter of the tube, the texture of the batch mix, and some other defects.

The fluorescent glass tube factory consists of four main areas: utility, batch, melting, and production area. The scope of the study is targeting the muffle area in which different types of defects occur during the process. These defects include; variation in the outer diameter of the tube, knots, stones, etc.

Advanced six-sigma tool (DMAIC) is applied on a case study to reduce process variation by capability index improvement and determine the reduced cost of outside diameter defect per million through using Part-Per-Million (PPM) Calculations. The reduction of outside diameter variation reached $50 \%$
\end{abstract}

\section{Introduction}

\subsection{Six Sigma application}

Today, the competition depends on how to continue developing and improving the product's quality and in the same time reducing production costs.

Six-Sigma procedure was applied on a manufacturing firm considering DMAIC as continuous loop [1]. The heart of the Six Sigma five-step process DMAIC (Define-Measure-AnalyzeImprove-Control) is used to solve quality problems of greater complexity and with the unknown root causes leading to projects improvement [11].

There are several "tools" that identify the causes of quality problems that are still widely used today, such as Pareto charts, process flowcharts, histograms, statistical process control charts, and cause-and-effect diagrams [2].

"Mervat A. Badr, Mechanical Engineering Department, National Research Centre, +201001026081\&drmabadr@gmail.com
There are many quality techniques that are applied on manufacturing processes. According to most modern approaches for productivity enhancement and waste elimination six sigma is considered one of the best methodologies [3].

Six-Sigma describes the high level of quality. It is known that 3 sigma(s) means that 2600 PPM are defective. The level of defects associated with Six Sigma is approximately 3.4 PPM [4-5].

To improve the manufacturing process capability, research was conducted using the lean six sigma method presenting a case study in the iron ore industry, [6]. The authors focused first on waste analysis using process activity mapping, and then evaluated the manufacturing process capability. Failure mode and effect analysis was used to develop the continuous improvement program.

Studies developed in recent years indicate that the Lean Six Sigma (LSS) has the potential to support organizations maintaining sustainability. The impacts of real LSS projects on the indicators related to the three pillars of organizational 
sustainability were investigated in a study presented by de Freitas et al [7].

The authors structured a questionnaire with 13 impacts of LSS, which was subsequently applied over 106 international LSS experts. They pointed to the necessity of directing the implantation and measurement models on different sectors each according to its characteristics.

A research paper aiming to improve the work standards presented establishments of the basic model of Web Content Management (WCM) for the logistics system in the automotive industry. The research results were developing basic strategic objectives, and performance measurement system linkages for improved organizational coordination, [8].

A study aiming at quality improvement in the chemical process industry was presented by Kim et al proposed a Six Sigma strategy applying the required techniques; existing and a new methodology to determine the precise sources of quality degradation problem, [9].

The problems encountered in supply chains are complex and difficult to define. Erbiyika and Saura applied Six Sigma in a supply chain of the automotive subsidiary industry, [10]. The study identified and analyzed the relevant potential and real defects using statistical methods.

The rough cut process comes after the measurement process, with a sharp cutter attached with cold water, the thermal shock hitting the tube causes it to break into the required length, with a rotational speed which is linked and related with the linear speed it produces tube/sec. The cutter is connected with the measurement device to give the order of cutting and accept or reject the cutting part; the output tube is transferred to another process cutting process by a conveyer. At the end of this conveyor, a lab test is performed on a sample of the output products.

Poor productivity of thermal power plant was the initiative of the study presented by Kumara et al to define the most critical cause for this problem which was found to be a high capacity waste at these plants [11]. The authors adopted the DMAIC approach focusing on the causes of capacity waste. Implementing the first phase of DMAIC; "Define", the study proved the capability of Six Sigma in defining the targeted issue.

In the case study "Six Sigma" was applied on a selected unit, using one year of collected data to find monthly capacity waste.
Pinjariet al presented a literature review on Six Sigma and how it affects the Indian industrial and production environment through the combination of the tools and techniques used in implementing Lean Manufacturing and Six Sigma Quality [12]. They also presented the Lean Six Sigma (LSS) methodology that could be implemented by Small and Medium Scale organizations to achieve improved levels of quality.

Hassan et al., presented a case study-based research that aimed the application of DMAIC methodology of Six-Sigma to improve a process by reducing the machine downtime [3]. Other research objectives are; increasing productivity \&product quality and minimizing operating expenses.

To analyze possibilities of applying the "six sigma" concept in a medium-sized company, Duraković, and Bašić applied DMAIC methodology, monitoring the textile process for two different periods, before and after improvement using statistical process control charts [13 4\#]. Dominant defect and its causes were identified. The method showed to be the suitable solution and the applied algorithm is promising for improving the process and allows easy calculation of the process parameters and process capability indices $\mathrm{Cp}$, Cpk.

Kučerová et al investigated the application of Lean Six Sigma in industrial companies, as one quality management significant methodologies that seek increasing productivity and improving quality [14 5\#]. The Lean Six Sigma system helps to effectively reduce any defective process. It focuses on the elimination of waste, targeting the elimination of non-value-adding activities to create continuous flow and shorten the process duration.

\section{Case Study: Application on Fluorescent Glass Tube Production Line}

The current study investigates the effect of applying the SixSigma technique on the manufacturing process of the fluorescent glass tube factory and performs cost-benefit analysis before and after the application of the methodology.

The project's aim was to decrease the number of defects occurring through the manufacturing process. According to the Pareto chart performed to determine the most weighted waste from the 8 types, the defect is considered the highest waste weight. Figure 1 illustrates Pareto chart for the waste types. 


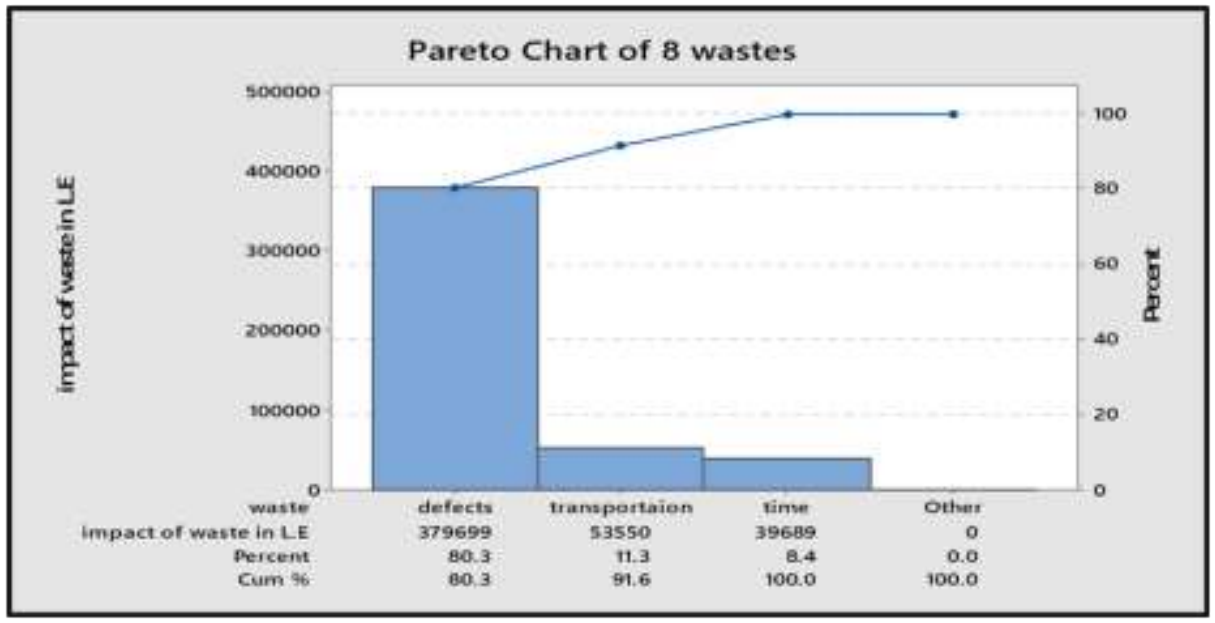

Figure 1: Pareto chart for waste types.

Most of the defects addressed in the current study start from the muffle area "the area where the glass start takes the shape of a tube" till the end of the cutting process. These defects are monitored then analyzed to reach the most recurrent defects and define their sources to eliminate them as possible.

Eight types of defects occur in the final product, each defect has different characteristic and are classified in the lab. Also, each defect has its cause for appearing in the product. According to the data received from the chemical lab for the classification of the defect, data shows that each defect has different weights. These defects are:

Outer diameter not good (OD NG): The specification limit of T9product; in our case study, outer diameter in is $28.8 \pm 0.7 \mathrm{~mm}$. A laser gauge fixed at the end of the pulling machine is used for measuring the tube diameter before the rough cut. If the actual diameter is above or under the acceptable variation, the laser sends an order to the cutting machine to cut the measured tube and push it away from the conveyer.

Cords: This defect is a wave-like line that appears on the top surface of the tube and results mainly from pulling operation.

Stones: It appears as a result of non-melted material on the top surface of the tube as the stones defect on glass or mainly from the corrosion of furnace interior wall. There is a specification limit for accepting or rejecting the tube.

Knots: It appears as the result of non-homogeneity between molten materials which cause gatherings in some areas on the top surface of the tube. Table

Airline: Airline is a defect that appears like a bubble line on the top surface this defect is not continuously repeated but it has high weight because when it occurs it shows the high number of defects. It often happens when the production planner decides to change the model to another.

Cracks: This type of defect cannot be accepted (i.e. no specification limits), it most likely happens as a result of change in atmosphere "annealing line area" after the tube exit from the furnace. The monitored data showed that the weight of the rack defect type is too small, which means that it can be neglected.

Crushes: This defect is most likely happens during the rough cut.

Other defects: Other defects contain two main types of defects bow and thick which appear at different points of time. Bow defect in glass tube means that the center line of the diameter in the tube moved from its position this defect often happen during the "annealing". While thick defect in glass tube means that the thickness of the outer diameter is over the limit.

These defects are divided into two categories measured defect and visual defects, the measured defects are; Outer Diameter Not Good (ODNG), thickness, and bow, the visual defects can be measured in the lab under the microscope and it comprises 5 types (stones, knots, cords, airline, and cracks). A sample was taken every 30 minutes to decide whether the process is in control or out of control. Measurable defects are measured in the quality room using measurement tools with very small gauge error, digital Vernier for measuring the outer diameter with standard error \pm 0.02 . A dial gauge is used for measuring thickness, length, and bow with standard error \pm 0.005 .

\section{Defect Reduction Using Six Sigma Methodology}

Data concerning different types of defects were collected on a regular basis, hence weekly reports of the number of each defect; in an excel sheet format, are prepared for the 8 months. Table 1 exhibits the first month (April) data as an example of the monthly data observed during the study, [12].

Using Minitab software Pareto chart is applied to analyze defects, Figure 2. 


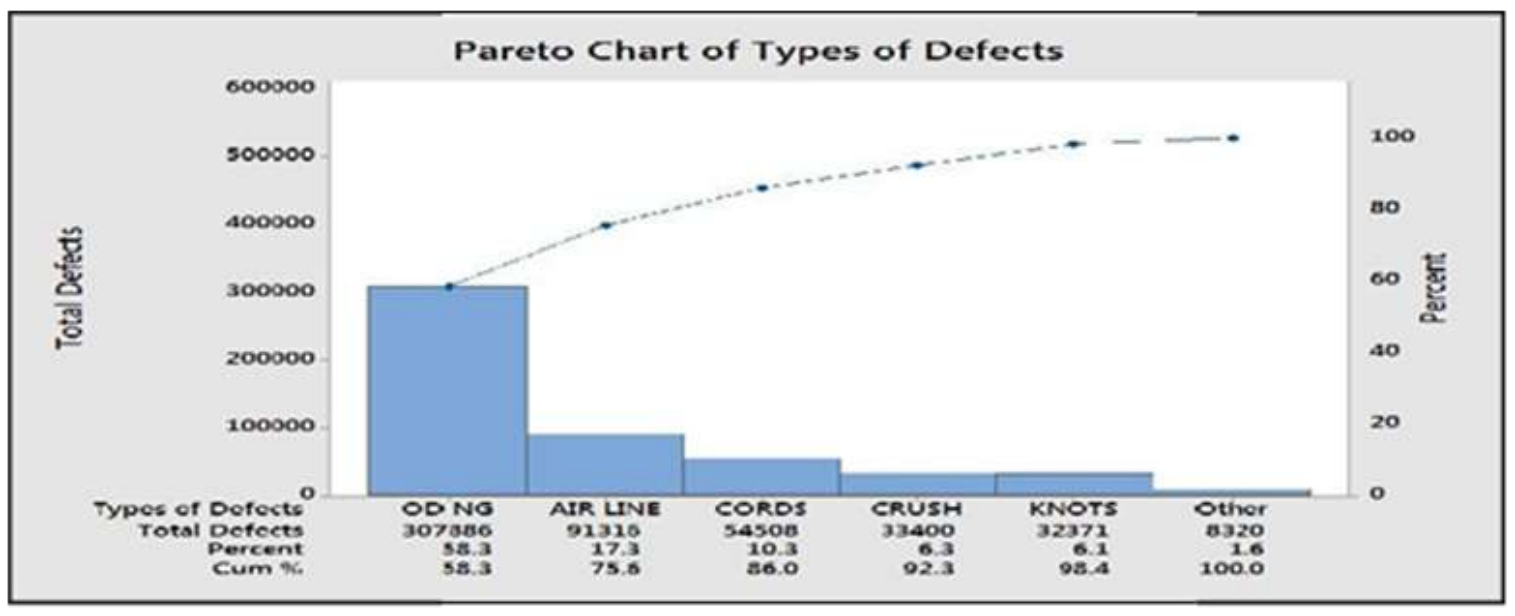

Figure 2: Pareto chart of glass tube defects

Table 1: NO-of-Defects / Day

\begin{tabular}{|c|c|c|c|c|c|c|c|c|c|c|}
\hline $\overrightarrow{\tilde{D}}$ & 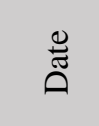 & 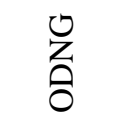 & $\begin{array}{l}\mathscr{\Xi} \\
\stackrel{0}{0} \\
\dot{\omega}\end{array}$ & $\begin{array}{l}\mathscr{0} \\
\stackrel{\Xi}{\Xi}\end{array}$ & ơ & $\stackrel{g}{:}$ & $\frac{\tilde{u}}{\tilde{U}}$ & $\stackrel{\tilde{D}}{E}$ & $\frac{\tilde{b}}{\vec{d}}$ & 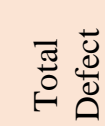 \\
\hline Fri & $01 / 04$ & 0 & 0 & 79 & 0 & 0 & 0 & 70 & 0 & 149 \\
\hline Sat & $02 / 04$ & 0 & 0 & 79 & 0 & 0 & 0 & 61 & 0 & 140 \\
\hline Sun & $03 / 04$ & 40 & 0 & 92 & 0 & 0 & 0 & 53 & 0 & 185 \\
\hline Mon & $04 / 04$ & 2686 & 0 & 128 & 15180 & 0 & 0 & 130 & 0 & 18124 \\
\hline Tue & $05 / 04$ & 20 & 1 & 172 & 112 & 0 & 0 & 78 & 0 & 383 \\
\hline Wed & $06 / 04$ & 68 & 0 & 90 & 0 & 0 & 0 & 107 & 0 & 265 \\
\hline Thu & $07 / 04$ & 0 & 0 & 117 & 0 & 0 & 0 & 162 & 0 & 279 \\
\hline Fri & $08 / 04$ & 0 & 0 & 81 & 0 & 0 & 0 & 84 & 0 & 165 \\
\hline Sat & $09 / 04$ & 186 & 0 & 75 & 0 & 0 & 0 & 103 & 0 & 364 \\
\hline Sun & $10 / 04$ & 112 & 0 & 73 & 0 & 0 & 0 & 66 & 0 & 251 \\
\hline Mon & $11 / 04$ & 0 & 0 & 100 & 0 & 0 & 0 & 118 & 0 & 218 \\
\hline Tue & $12 / 04$ & 110 & 0 & 87 & 0 & 0 & 0 & 78 & 0 & 275 \\
\hline Wed & $13 / 04$ & 0 & 0 & 87 & 0 & 0 & 0 & 102 & 0 & 189 \\
\hline Thu & $14 / 04$ & 39 & 0 & 83 & 0 & 0 & 0 & 64 & 0 & 186 \\
\hline Fri & $15 / 04$ & 13 & 0 & 82 & 0 & 0 & 0 & 70 & 0 & 165 \\
\hline Sat & $16 / 04$ & 93 & 0 & 77 & 0 & 0 & 0 & 60 & 0 & 230 \\
\hline Sun & $17 / 04$ & 170 & 0 & 56 & 0 & 0 & 0 & 48 & 0 & 274 \\
\hline Mon & $18 / 04$ & 316 & 0 & 83 & 0 & 0 & 0 & 67 & 0 & 466 \\
\hline Tue & $19 / 04$ & 6632 & 0 & 178 & 0 & 69699 & 0 & 152 & 0 & 76661 \\
\hline Wed & $20 / 04$ & 0 & 0 & 102 & 0 & 0 & 0 & 54 & 0 & 156 \\
\hline Thu & $21 / 04$ & 36 & 0 & 101 & 0 & 0 & 0 & 63 & 0 & 200 \\
\hline Fri & $22 / 04$ & 5454 & 0 & 147 & 0 & 0 & 0 & 150 & 0 & 5751 \\
\hline Sat & $23 / 04$ & 15181 & 0 & 99 & 0 & 0 & 0 & 106 & 0 & 15386 \\
\hline Sun & $24 / 04$ & 4212 & 0 & 103 & 0 & 0 & 0 & 74 & 0 & 4389 \\
\hline Mon & $25 / 04$ & 182 & 0 & 101 & 0 & 0 & 0 & 74 & 0 & 357 \\
\hline Tue & $26 / 04$ & 0 & 0 & 101 & 0 & 0 & 0 & 79 & 0 & 180 \\
\hline Wed & $27 / 04$ & 0 & 0 & 63 & 0 & 0 & 0 & 46 & 0 & 109 \\
\hline Thu & $28 / 04$ & 125 & 0 & 158 & 0 & 0 & 0 & 333 & 0 & 616 \\
\hline Fri & $29 / 04$ & 76 & 0 & 109 & 0 & 0 & 0 & 132 & 300 & 617 \\
\hline Sat & $30 / 04$ & 77 & 0 & 78 & 0 & 0 & 0 & 44 & 0 & 199 \\
\hline
\end{tabular}

As shown in Figure 2 defects that occurred in the production process are mainly due to two types; ODNG and Air Line. The primary analysis for the data shows that there are three main causes responsible for this high number of defects. The first; and most affecting, is switching from one model to another which means changing the tube specification (diameter and thickness) 
causing faulty dimensioned tubes. Changing the model is also a cause of airline defect type but with much lower weight than ODNG.

The second reason is sleeve maintenance as sleeve function is to drag the product from the furnace in a tube form so it is expected that defective product will result if there is a problem in sleeve operation (in Table 1: Tuesday 19/4 airline number of defects 69699). The third reason for the Airline defect is the power shutoff (electricity breakdown). Although there are two backup diesel generators (of two megawatts), the time elapsed for starting up causes the appearance of this defect type.

Reviewing the results of the previously performed analysis it was suggested to focus on problems concerning the ST-T9 model and postpones the investigation of problems that result from changing the tube model. Hence, another Pareto chart is performed for the ST-T9 model discarding other models. Figure 3 illustrates the Pareto chart of the defects of the T9 model.

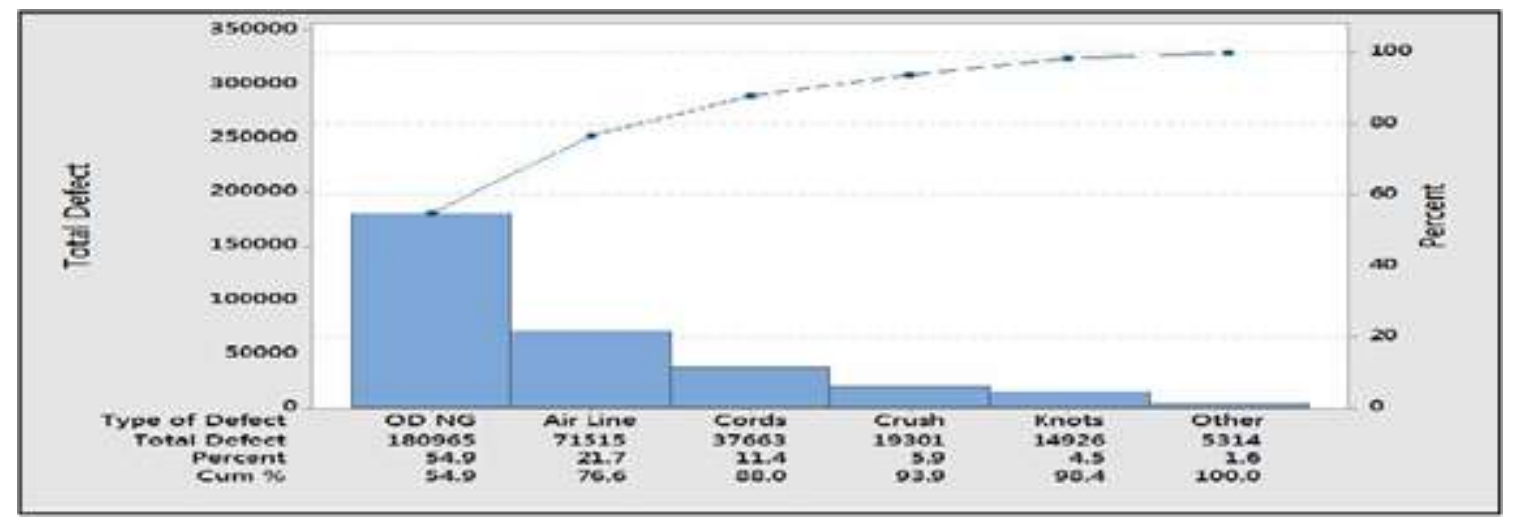

Figure 4: Pareto chart of glass tube defects (T9 type only).

From Figure 4, it is clear that ODNG and Air Line defects are still constituted $80 \%$ of the defects. Pareto chart technique is used to measure numbers, but it can't measure the criticality of the defect on the product, so the next step is measuring the criticality of each defect to focus on the problems causing significant defect; highly frequent and critical. From a criticality point of view, cracks have the most and the first importance as "No Crack Is Allowable", while the second critical defect is "ODNG". Both ODNG and Air Line defect types are relatively connected; solving ODNG will reduce some of the problems related to Air Line, so our study for applying six-sigma will typically focus on solving ODNG.

\subsection{III.1. Define phase}

Define phase is considered the most important phase, as it deals with diagnosing and identifying the problem, it requires details that represent a lot of information, it will typically focus on ODNG defect type The details include:

Product or model name which has the problem that is the focus of the study; ST-T9 model, in this case, Duration study its start and end, total input and it's a total defect for all types also the total defect for ODNG, Improvement date start, and end, control date start, Pareto chart results, Number of defects that appear on the product and number of defect concerning with ODNG, Type of defect variable or attribute, goal or target to be achieved (reduction in the number of defects). In the current case study
(ODNG) defects should be reduced to $50 \%$ of their value according to factory $R \& D$ requirements. A sheet containing these details is exhibited in Appendix B.

\subsection{III.2. Measuring phase}

As previously mentioned a laser gauge is used to measure the diameter of the tube. Mathematical calculations are performed based on the signal received from the laser gauge to determine the actual diameter of the tube (specification limit for ST-T9 product outer diameter is about $28.8 \pm 0.7 \mathrm{~mm}$ ). The laser gauge is calibrated; every 15 days, to check its accuracy using two Japanese standard references with the different diameter $(10.022 \mathrm{~mm} \pm 1 \mu)(40.015 \mathrm{~mm} \pm 3 \mu)$.

Many Measurement System Analysis (MSA) tools are used in the measure phase to determine variation or errors in system measurements, as measurement errors affect product inspection, deposition, service acceptability, statistical process control analysis, and profitability.

Verifying the measurement system output, several sample groups (52 groups) were collected at different hours; each group consists of five samples. Measuring the variation outcome from the tubes using both leaser system and manual measurement "Digital Vernier", the results of the readings collected and prepared for analyzing it on Minitab software. The output Minitab report demonstrating the behavior of the sampled data is exhibited in Figure 5. 


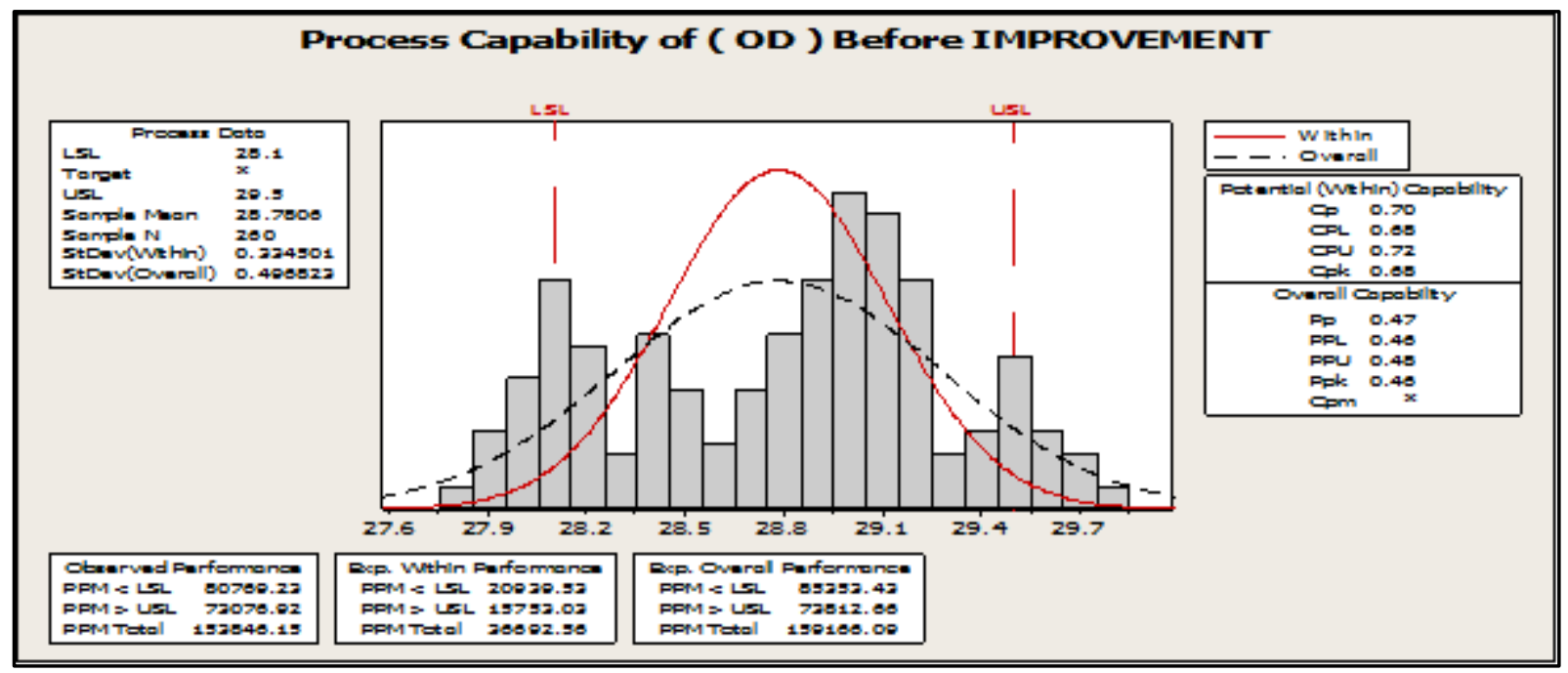

Figure 5: Distribution chart for the sample data before improvement

The chart in Figure 5 clarifies that the data does not follow the normal distribution curve; this is due to the four main causes of OD defects obtained from the preliminary analysis, which means that there are four normal distribution curves. Process capability (CPK) indicates that the process is incapable if it is below 1.00, in the current case CPK; obtained from Minitab, is equal to 0.68 with approximately $2.04 \sigma$ sigma level. The obtained process performance (PPK) indicates that the production percentage will decrease till it reaches $46 \%$ in a period time from 6 to 12 months. $\mathrm{X}$-bar-S control chart is shown in Figure 6, while figure7 exhibits the process capability six-pack.

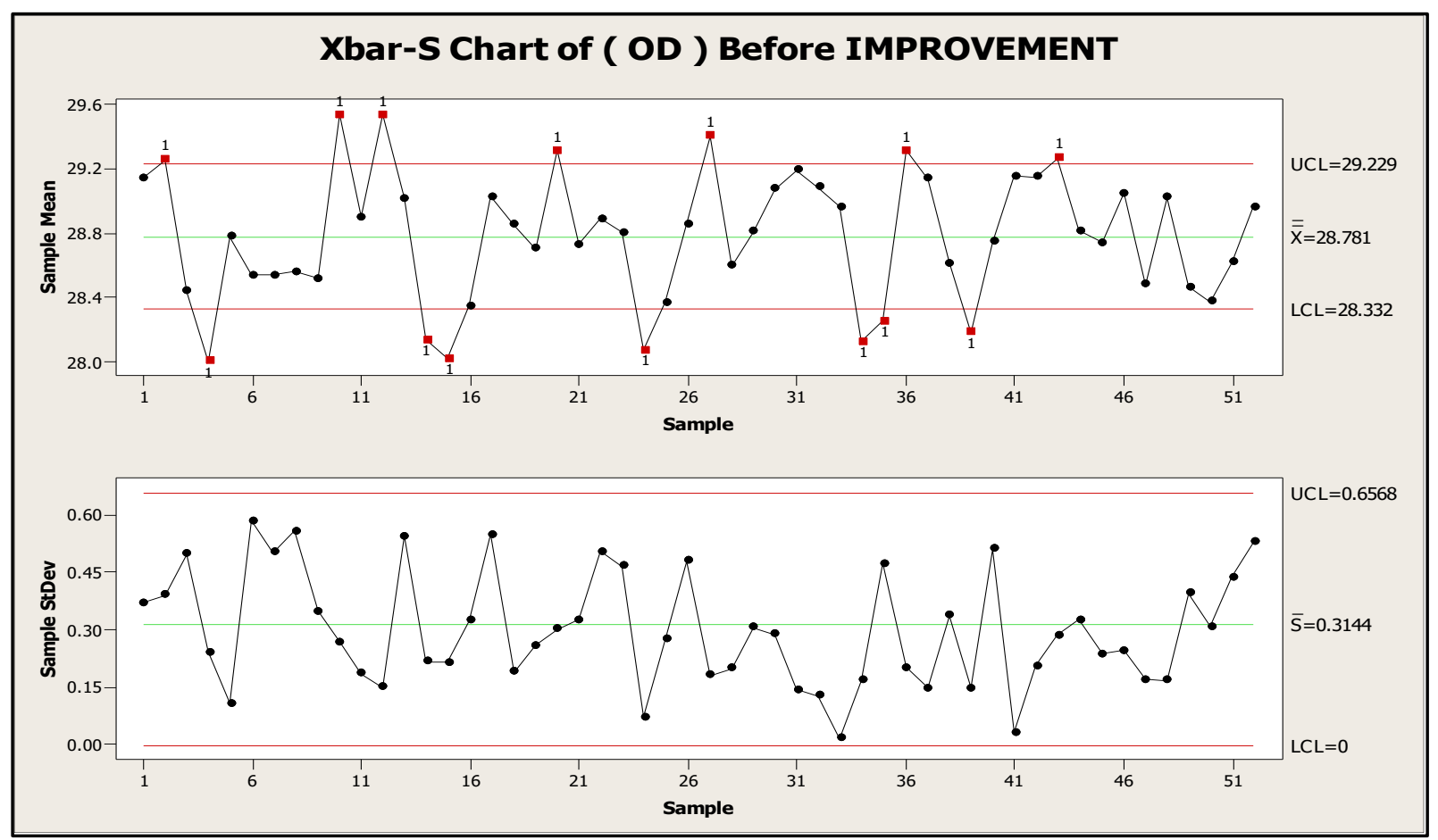

Figure 6: X-bar-S control chart process before improvement 


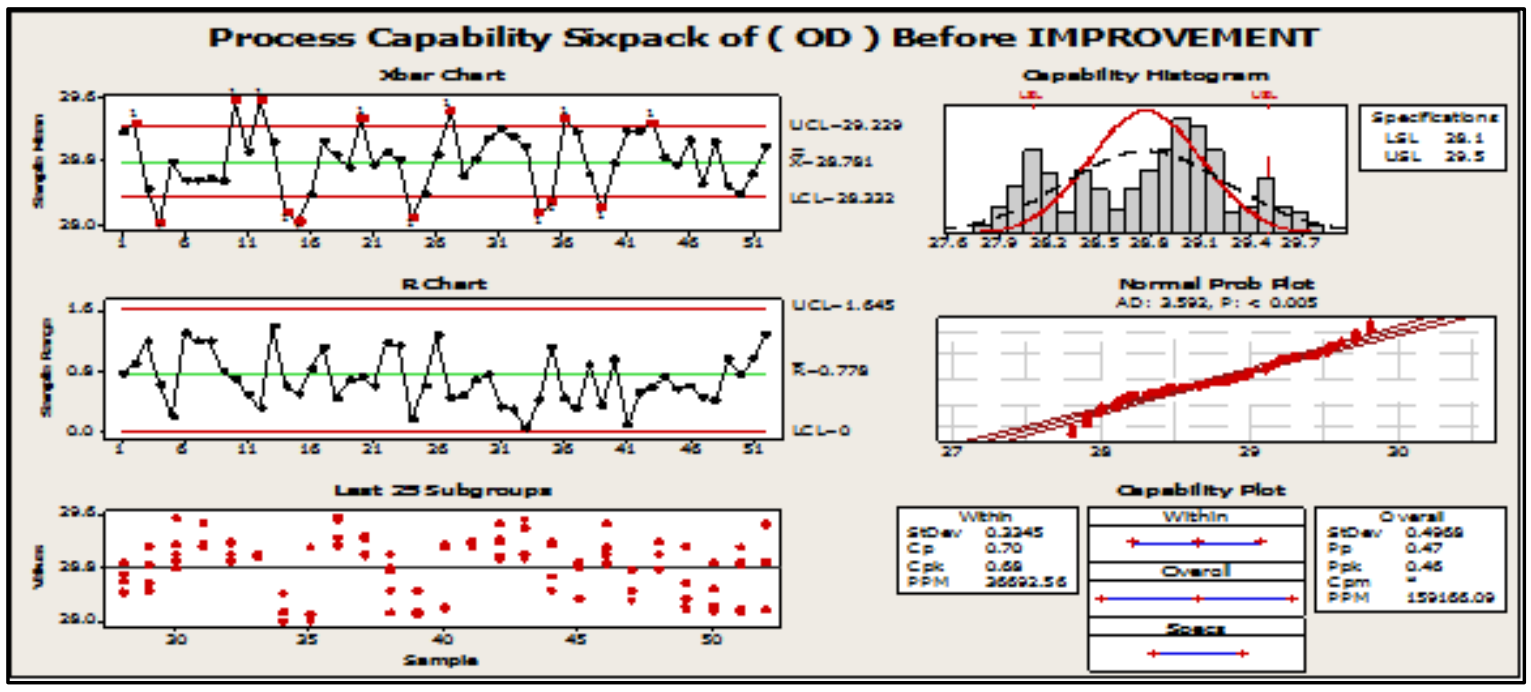

Figure 7: Process capability six-pack before improvement

The charts demonstrate the behavior of the samples and how much it is scattered around the centerline; it also indicates that there is no control on the process "random behavior".

\subsection{III.3. Analysis Phase}

In the analysis phase, causal hypotheses are to be developed to identify some root causes and validate hypotheses. Figure 8 exhibits the fishbone diagram of different causes that are related to the main 6 parameters (Machines, Personnel, Material, Method, Measurements, and environment).

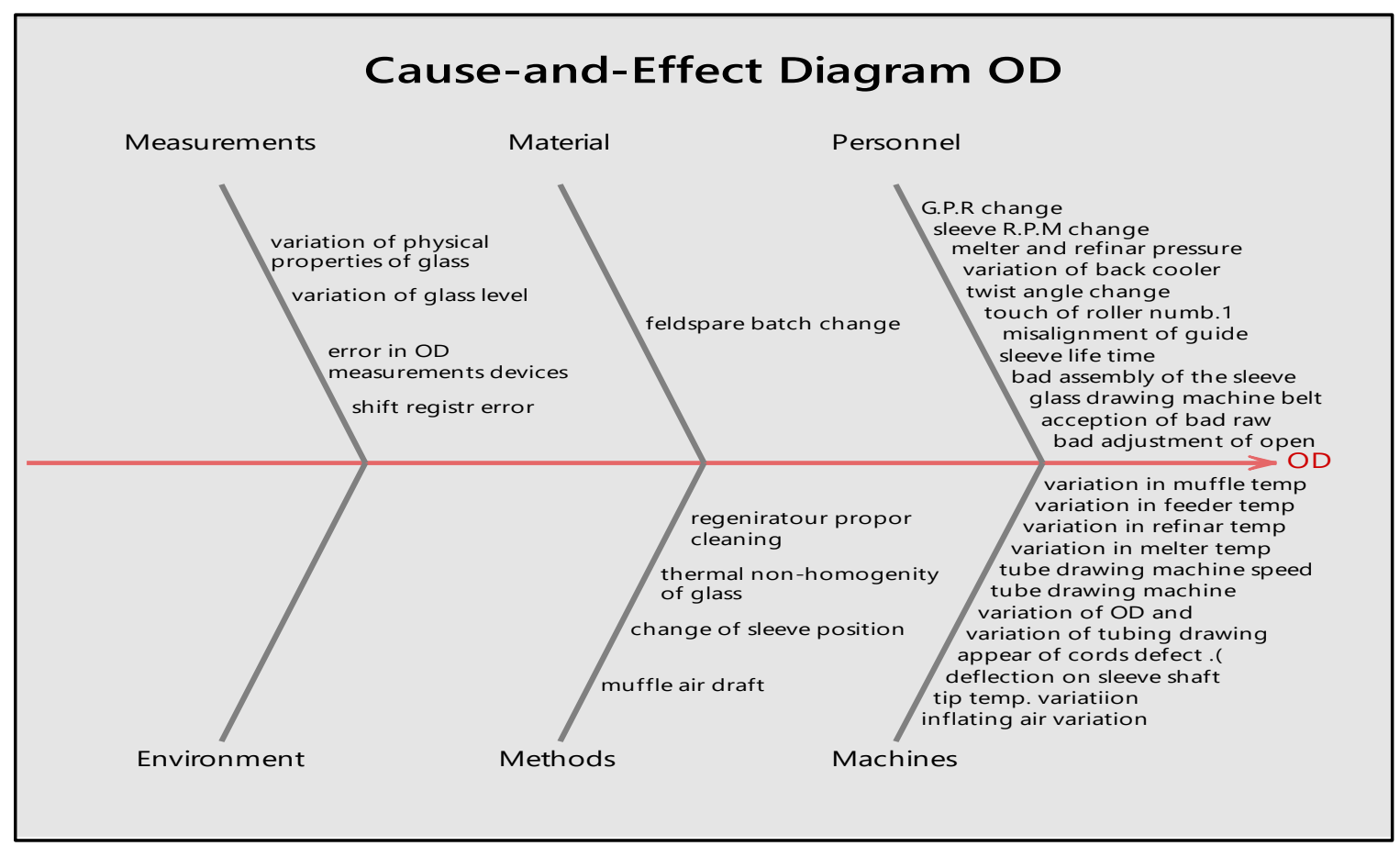

Figure 8: Cause and effect diagram

As discussed above; sec. III.2, measurement parameter is already verified and calibrated. For other parameters all causes; depicted in Figure 8, have been tested and verified except the machines parameter causes are analyzed using the Pareto chart. The hypothesis results for the most weighted causes related to machine parameters are exhibited in Figure 9. 


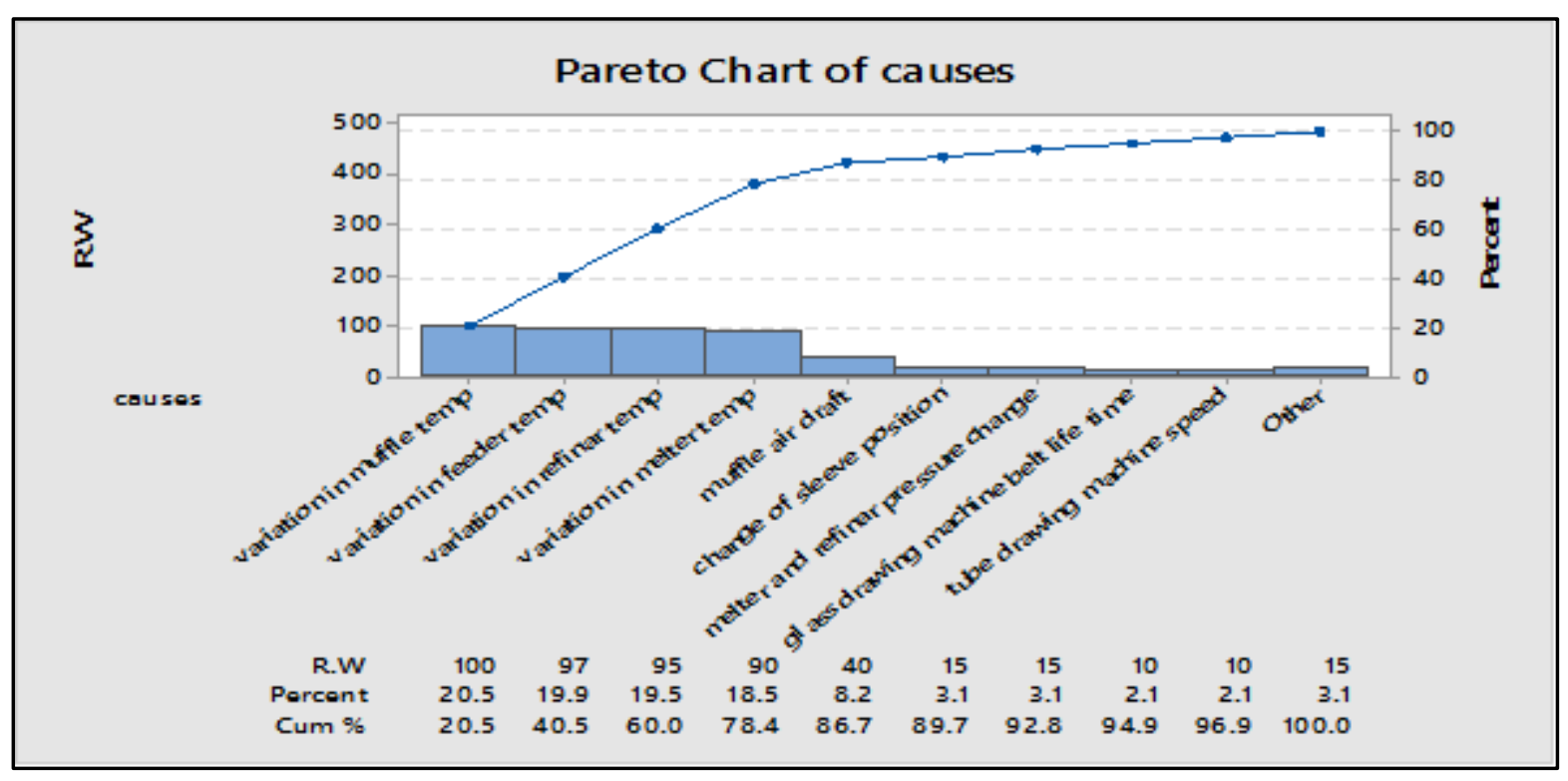

Figure 9: Pareto chart for machine causes

The chart; in Figure 9, demonstrates that $80 \%$ of the problem due to 4 causes (variation in muffle temp, variation in feeder temp, variation in refiner temp, and variation in melting furnace temp). As soon as these causes are determined an action plan has to be applied. Studying the 4 root causes a decision of the suitable corrective actions and what should be adjusted is taken. Table 2 demonstrates the four root causes with the action plan.

Table 2: The action plan for the identified causes

\begin{tabular}{|c|c|c|c|c|c|c|c|c|c|c|}
\hline $\begin{array}{l}\text { CAUSE } \\
\text { NO. }\end{array}$ & $\begin{array}{c}\text { ROOT } \\
\text { CAUSES }\end{array}$ & $\begin{array}{c}\text { CORRECTIVE } \\
\text { ACTION }\end{array}$ & T.C & Priority & What & Who & Where & How & When & $\begin{array}{l}\text { Person in } \\
\text { control }\end{array}$ \\
\hline 1 & $\begin{array}{l}\text { variation in } \\
\text { muffle temp }\end{array}$ & $\begin{array}{l}\text { Adjust muffle temp. (TC) } \\
\text { within temp. Control } \\
\text { Curve }\end{array}$ & $\begin{array}{l}\mathrm{Up} 10 \mathrm{TC} \text { for } \\
\text { all point temp. }\end{array}$ & A & \begin{tabular}{|l} 
OD \\
adjust
\end{tabular} & $\begin{array}{c}\text { Prod. } \\
\text { engineer }\end{array}$ & $\begin{array}{c}\text { muffle } \\
\text { area }\end{array}$ & $\begin{array}{l}\text { By temp. } \\
\text { control } \\
\text { system }\end{array}$ & & $\begin{array}{l}\text { Production } \\
\text { section } \\
\text { manager }\end{array}$ \\
\hline 2 & $\begin{array}{l}\text { variation in } \\
\text { feeder temp }\end{array}$ & $\begin{array}{l}\text { Adjust feeders temp. (TC) } \\
\text { within temp. Control } \\
\text { Curve. }\end{array}$ & $\begin{array}{l}\text { up } 2 \mathrm{TC} \text { for } \\
\mathrm{F} 1 \& \mathrm{~F} 2\end{array}$ & A & \begin{tabular}{|} 
OD \\
adjust
\end{tabular} & $\begin{array}{l}\text { Furnace } \\
\text { engineer }\end{array}$ & $\begin{array}{c}\text { feeders } \\
\text { area }\end{array}$ & $\begin{array}{l}\text { By temp. } \\
\text { control } \\
\text { system }\end{array}$ & & $\begin{array}{l}\text { Furnace } \\
\text { section } \\
\text { manager }\end{array}$ \\
\hline 3 & $\begin{array}{l}\text { variation in } \\
\text { refiner temp }\end{array}$ & $\begin{array}{l}\text { Adjust refiner temp. (TC) } \\
\text { within temp. Control } \\
\text { Curve }\end{array}$ & $\begin{array}{c}\text { down } 5 \mathrm{TC} \text { for } \\
\text { refiner }\end{array}$ & B & \begin{tabular}{|} 
OD \\
adjust
\end{tabular} & $\begin{array}{l}\text { furnace } \\
\text { engineer }\end{array}$ & $\begin{array}{c}\text { refiner } \\
\text { area }\end{array}$ & $\begin{array}{l}\text { By temp. } \\
\text { control } \\
\text { system }\end{array}$ & & $\begin{array}{c}\text { furnace section } \\
\text { manager }\end{array}$ \\
\hline 4 & $\begin{array}{c}\text { variation in } \\
\text { milting temp }\end{array}$ & $\begin{array}{l}\text { Adjust melting temp. } \\
\text { (TC) within temp. } \\
\text { Control Curve }\end{array}$ & $\begin{array}{c}\text { down } 5 \text { TC for } \\
\text { melting area } \\
\text { (O.P) }\end{array}$ & B & \begin{tabular}{|} 
OD \\
adjust
\end{tabular} & $\begin{array}{l}\text { furnace } \\
\text { engineer }\end{array}$ & $\begin{array}{l}\text { Milting } \\
\text { area }\end{array}$ & $\begin{array}{l}\text { By temp. } \\
\text { control } \\
\text { system }\end{array}$ & & $\begin{array}{c}\text { furnace section } \\
\text { manager }\end{array}$ \\
\hline
\end{tabular}

\subsection{III.4. Improving Phase}

At the end of the study period, the problems in the line were defined and the root causes were determined. Applying the action plan and its corrective actions is the first step in the improvement phase which was applied over two months. In order to check the impact of improvement activities, the sampling procedure applied before improvement is used after improvement to evaluate the results. The collected data are inserted on Minitab to analyze the improvement (change) and obtain the current state for the production process. The output reports of Minitab demonstrate the behavior of the sampled data. Figure10 exhibits the Distribution chart for the sample data after implementing the corrective action. 


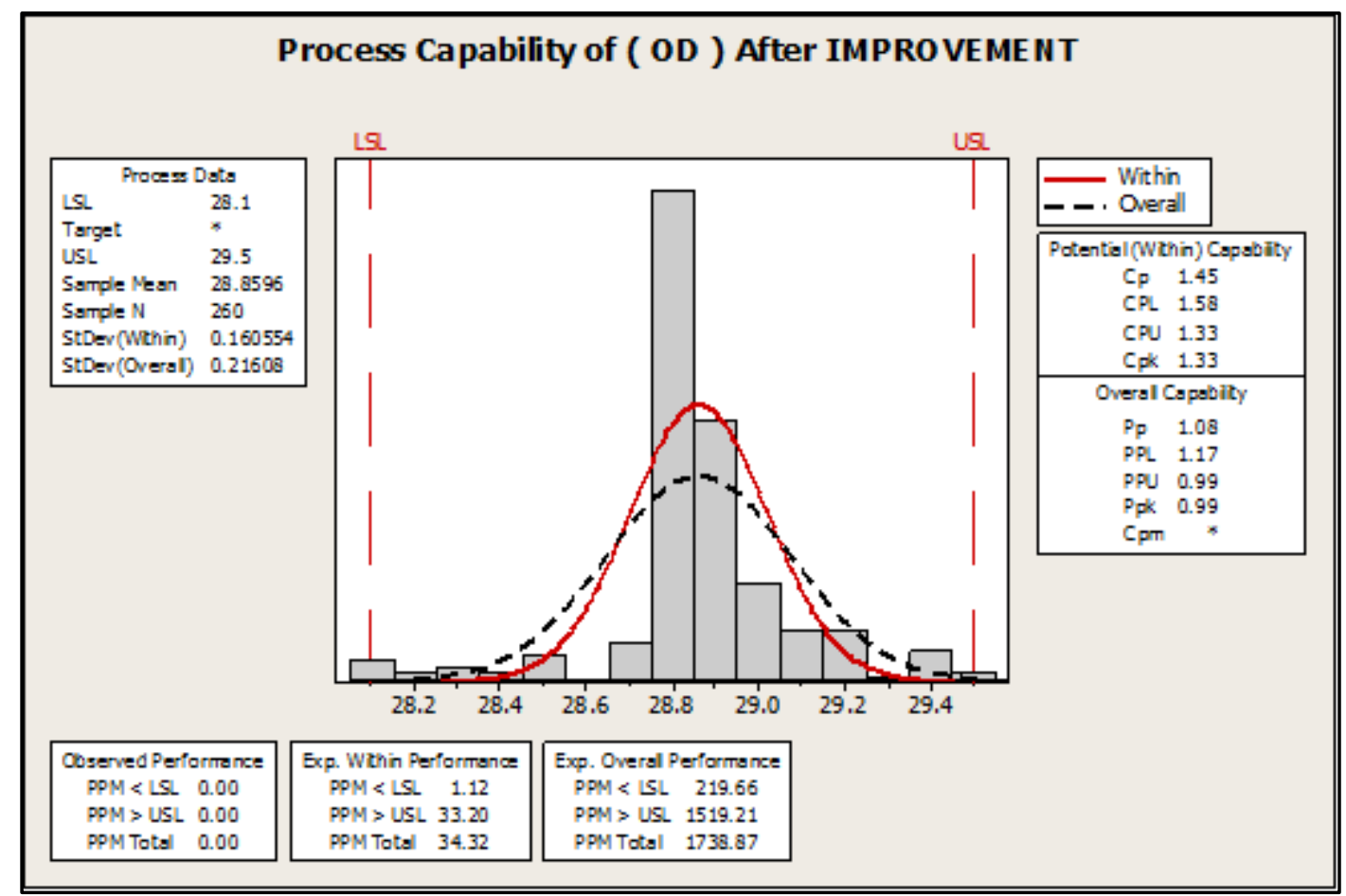

Figure 10: Distribution chart for the sample data after improvement

The chart clarifies that the data now had become more fitted to the normal distribution curve. The Process Capability (CPK) indicator had increased up to 1.33 which means that the process capability is acceptable. The process performance (PPK) indicates that it will reach $99 \%$ in a period time from 6 to 12 months. The sigma levels now have become 3.99 o. Also, the Xbar-S chart explains the process control and how much changes after the improvement. Figures 11, 12 illustrate the X-bar-S control chart process and process capability six-pack after implementing the corrective-action, respectively. 


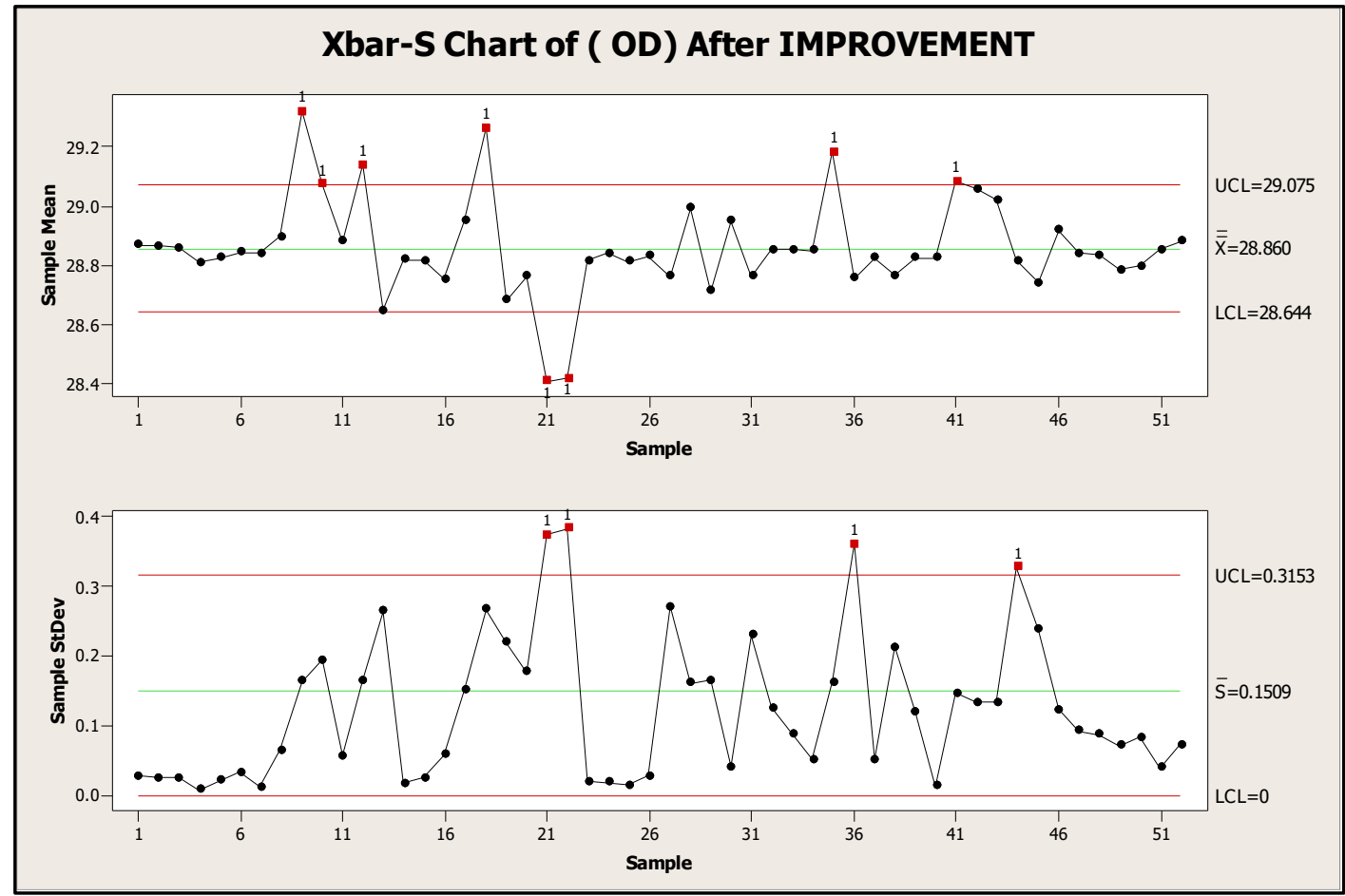

Figure 11: $X$-bar-S control chart process after improvement

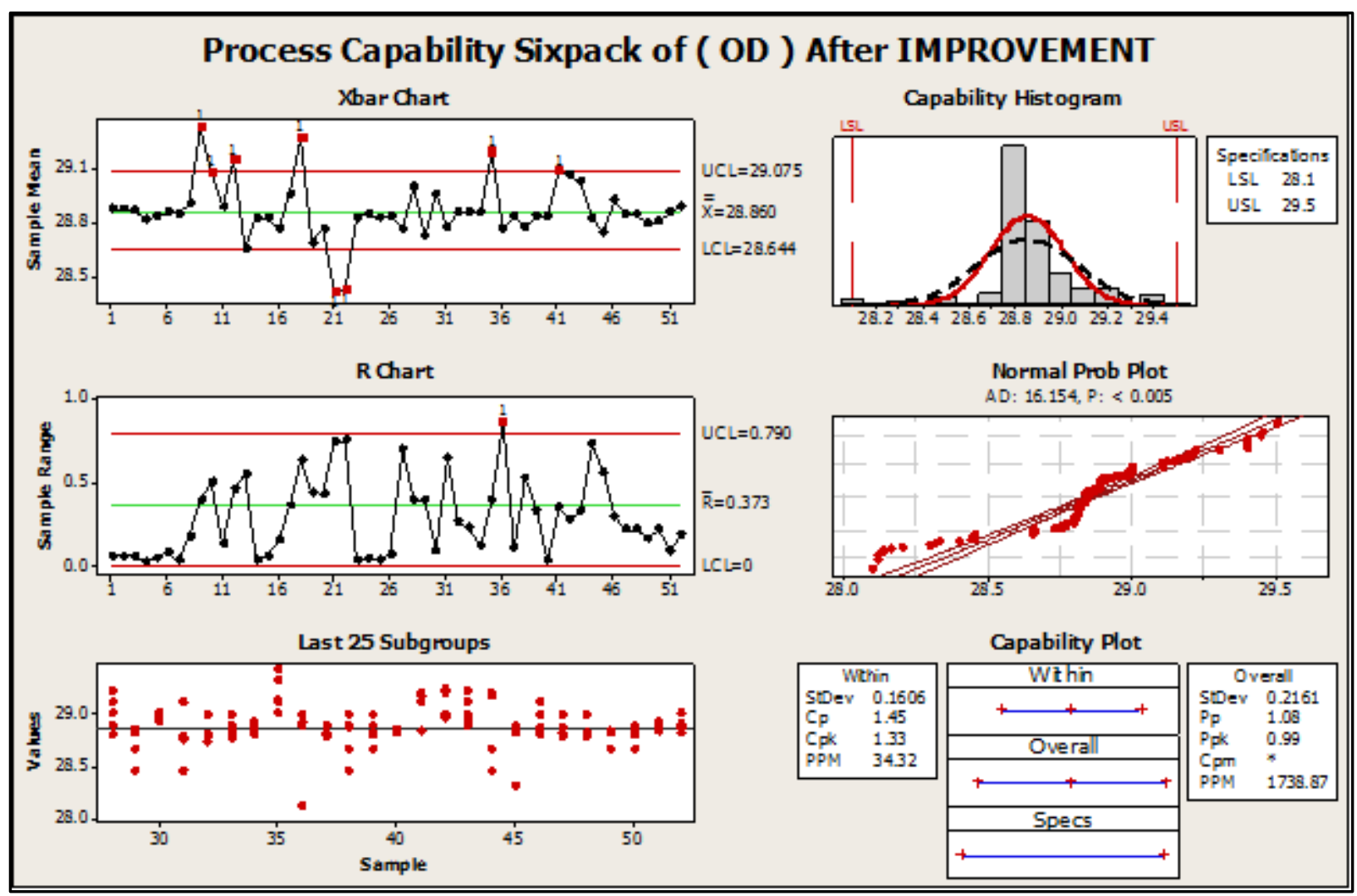

Figure12: Process capability six-pack after improvement 


\section{Results \& Discussions:}

The production process a number of defects product for the OD type was monitored for 3 months. Change in the temperature curve and number of defect per million during this period gathered and calculated.
Table 3 exhibits the first corrective action for the temperature changes. Table 4 represents the defect parts per million and cost reduced while Table 5 represents a comparison of the results during improvement.

Table 3: Corrective actions for the temperature changes

\begin{tabular}{|c|c|c|c|c|c|c|c|c|c|c|c|c|c|}
\hline $\begin{array}{l}\bar{E} \\
\stackrel{0}{0} \\
\Sigma\end{array}$ & $\vec{\Xi}$ & 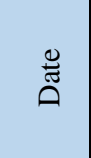 & 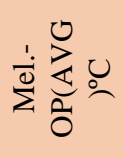 & 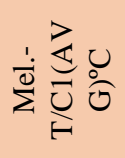 & 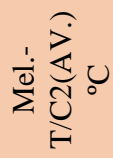 & 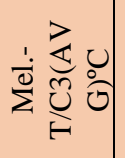 & 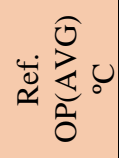 & 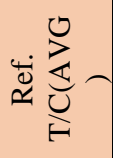 & 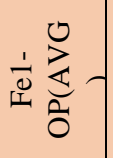 & 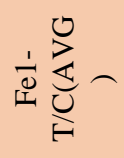 & 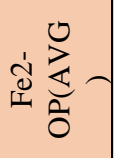 & 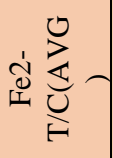 & $\begin{array}{c}\text { FURNA } \\
\text { CE } \\
\text { CHANG } \\
\text { ES }\end{array}$ \\
\hline August & Mon & $22 / 08$ & 1470.8 & 1198.5 & 1292.8 & 1385.0 & 1153.0 & 1094.0 & 1112.2 & 1147.0 & 1106.5 & 1117.5 & \\
\hline August & Tue & $23 / 08$ & 1471.8 & 1198.8 & 1293.5 & 1387.1 & 1152.7 & 1094.0 & 1111.0 & 1146.0 & 1105.7 & 1117.0 & \\
\hline August & wed & $24 / 08$ & 1473.0 & 1196.9 & 1294.6 & 1388.7 & 1153.1 & 1097.0 & 1112.2 & 1147.5 & 1106.2 & 1117.8 & $\begin{array}{l}\text { Adjust } \\
\text { feeders } \\
\text { temp. } \\
\text { (TC)up2 } \\
\text { TC for } \\
\text { F1 \&F2 }\end{array}$ \\
\hline August & Thu & $25 / 08$ & 1473.0 & 1198.5 & 1294.6 & 1389.5 & 1154.3 & 1097.0 & 1112.7 & 1147.5 & 1107.2 & 1117.8 & \\
\hline August & Fri & $26 / 08$ & 1471.8 & 1198.5 & 1296.3 & 1388.7 & 1153.6 & 1097.0 & 1113.9 & 1147.5 & 1107.0 & 1117.8 & \\
\hline August & Sat & $27 / 08$ & 1472.6 & 1198.9 & 1293.9 & 1386.6 & 1153.5 & 1097.0 & 1112.4 & 1148.0 & 1107.3 & 1118.0 & \\
\hline
\end{tabular}

Table 4: Cost saving and reduced parts per million

\begin{tabular}{|c|c|}
\hline Total production units for T9 40wt & $6,000,00$ \\
\hline Part Per Million Reduced & 36,330 \\
\hline Reduced Cost of OD defect per million (L.E) & 54,724 \\
\hline
\end{tabular}

Table 5: Obtained Results

\begin{tabular}{|l|c|c|c|c|c|}
\hline \multicolumn{1}{|c|}{$\begin{array}{c}\text { Goal } \\
\text { S }\end{array}$} & $\begin{array}{c}\text { Curren } \\
\mathbf{t} \text { state }\end{array}$ & $\begin{array}{c}\text { Targe } \\
\mathbf{t}\end{array}$ & $\begin{array}{c}\text { Actua } \\
\mathbf{l}\end{array}$ & Improvement Level & $\begin{array}{c}\text { Number } \\
\text { of Days }\end{array}$ \\
\hline Increase process sigma level $(\sigma)$ & 2.04 & 3.9 & 4.0 & 1.96 & \multirow{2}{*}{60} \\
\cline { 1 - 4 } $\begin{array}{l}\text { Reduce Cost of outside diameter defects } \\
\text { per million (LE) }\end{array}$ & 18,241 & 9,121 & 9,121 & $(9,121)$ & \multirow{2}{*}{60} \\
\hline $\begin{array}{l}\text { Decrease Process variation with a } \\
\text { capability index improvement(CPK): }\end{array}$ & 0.68 & 1.30 & 1.33 & 0.65 & $(6,055)$ \\
\hline Part Per Million defect to be reduced: & 11,055 & 5,528 & 5,000 & \\
\hline
\end{tabular}

\section{Conclusion}

Comparing the output data before and after the corrective action indicates that a huge improvement appeared which means that the corrective actions taken are effective.

Analyzing both outputs it is seen that:
1. The cost due to outside diameter defects is reduced by about $50 \%$ which was the study target.

2. The PPM defect is reduced by about $55 \%$.

3. Change in CPK indicator moved from 0.68 to 1.33 about $50 \%$ increases in the capability 
4. PPK indicator increased from 0.46 to 0.99 about $45 \%$ changes this means that the process performance had improved reaching 4 sigma-level.

5. The above improvements were achieved in two months (60 days)

Once the improvement has been achieved and results are documented, it is essential to continue to measure the performance of the process routinely, adjusting its operation. It is very important to ensure that the process is in control and the variation in outer diameter gradually decreasing.

\section{References}

[1] Tauseef Aized, Total Quality Management and Six Sigma, 2012.

[2] Star bird. Business excellence: Six Sigma as a management System: A DMAIC approach to improving Six Sigma management Processes. Annual Quality Congress Proceedings, Milwaukee, 2002

[3] R. Dan Reid, Nada R. Sanders, Operations Management an Integrated Approach, John Wiley Sons, 4th edition, 2011.

[4] Ram Naresh, "A Modern approach to operations management", New Age International, 4th edition, Mar, 2005.

[5] Mahmoud M.A. Sayed, "Applying Total Quality Management in Research and Development", International Journal of Innovative Research and Development, Vol. 7, Issue 3, 2014.

[6] Garza-Reyes, J.A., "Green lean and the need for Six Sigma". Int. J. Lean Six- Sigma. 2015.

[7] Sri Indrawati, Muhammad Ridwansyah, "Manufacturing Continuous Improvement Using Lean Six Sigma: An Iron Ores Industry Case Application", Procedia Manufacturing 4, 528 - 534, 2015.

[8] Jessica Galdino de Freitas, Helder Gomes Costa, Fernando Toledo Ferraz, "Impacts of Lean Six Sigma over organizational sustainability: A survey study". Journal of Cleaner Production 156, 262-275, 2017.

[9] F. De Felice. A. Petrillo, "Optimization of Manufacturing System through World Class Manufacturing". IFAC-Papers on Line 48-3, 741-746, 2015.

[10] Minjin Kim, Young-Hak Lee, In-Su Han, Chonghun Han, "Quality Improvement in the Chemical Process Industry using Six Sigma Technique". Process Systems Engineering, 2003.

[11] Pardeep Kumara, P.C. Tewarib and Dinesh Khanduja, "Six Sigma application in a process industry for capacity waste reduction: A case study, Management Science Letters 7, 423-430, 2017. www.GrowingScience.com $/ \mathrm{msl}$

[12] Harun Pinjari, S. N. Teli, Lokpriya Gaikwad, "Lean Six Sigma Applications", Conference: 3 International Conferences on Engineering Confluence (Equinox 2017)

[13] Rohail Hassan, Maran Marimuthu and Manmeet MahinderjitSingh, "Application of Six-Sigma for Process Improvement in Manufacturing Industries: A Case Study", International Business Management 10 (5): 676-691, 2016.

ISSN: 1993-5250 @ Medwell Journals
[14] Benjamin Duraković, Hazim Bašić, "Textile Cutting Process Optimization Model Based on Six Sigma Methodology in a Medium-Sized Company", Periodicals Of Engineering And Natural Sciences Vol. 1 No. 1, 2013.

Available online at: http://pen.ius.edu.ba. ISSN 2303-4521

[15] Marta Kučerová, Miroslava Míkva, Dagmar Rusková, "Lean Six Sigma Implementation in Industrial Companies", Quality ISSUES and insights In THE $21^{\text {st }}$ century Vol. 2, No. 1, 2013.

ISSN 2029-9575

[16] Hikmet Erbiyika, Muhsine Sarua, "Six Sigma Implementations in Supply Chain: An Application for an Automotive Subsidiary Industry in Bursa in Turkey". Procedia - Social and Behavioural Sciences $195,2556-2565,2015$

[17] Mohamed AbdelSattar, Seif Ehab, "Improving Productivity Using Six Sigma Methodologies: A Case Study on a Fluorescent Glass Tube Factory", Graduation project, Mech. Eng. Dept., CIC- Cairo, 2017. 